\title{
Recent patent applications in antibody fragments: an academic update from the EU
}

\author{
Julien Muzard
}

Thesers he feature "Recent patent applications in antibody fragments" (Nat. Biotechnol. 29, 231, 2011) focused mainly on patents from US-based companies dealing in molecular engineering. This is a challenging area with applications and potential for basic research and immunodiagnostic (protein affinity reagent for in vitro detection and noninvasing imaging) as well as modern biotherapeutic (in vivo targeting). Furthermore, US 20100330661 claims some peptide sequences that dramatically differ from antibody fragment motifs, including complementary-determining regions (CDRs), which are not directly related to the design, generation or characterization of antibody fragments.

Therefore, an up-to-date table reviewing recently patented antibody fragments is presented, with a focus on European, state-of-theart (e.g., affinity reagent, highly stable, fully human) antibody fragment molecules isolated in both academia and industry (Table 1). The examples below add to our understanding of the research and development of engineered antibody fragments and also serve to demonstrate how academic research in Europe and elsewhere can be as productive in terms of patenting as biotech companies in this potential multi-billion dollar market.

COMPETING FINANCIAL INTERESTS

The author declares no competing financial interests.

Table 1 Recent patent applications in antibody fragments: an academic update from the EU

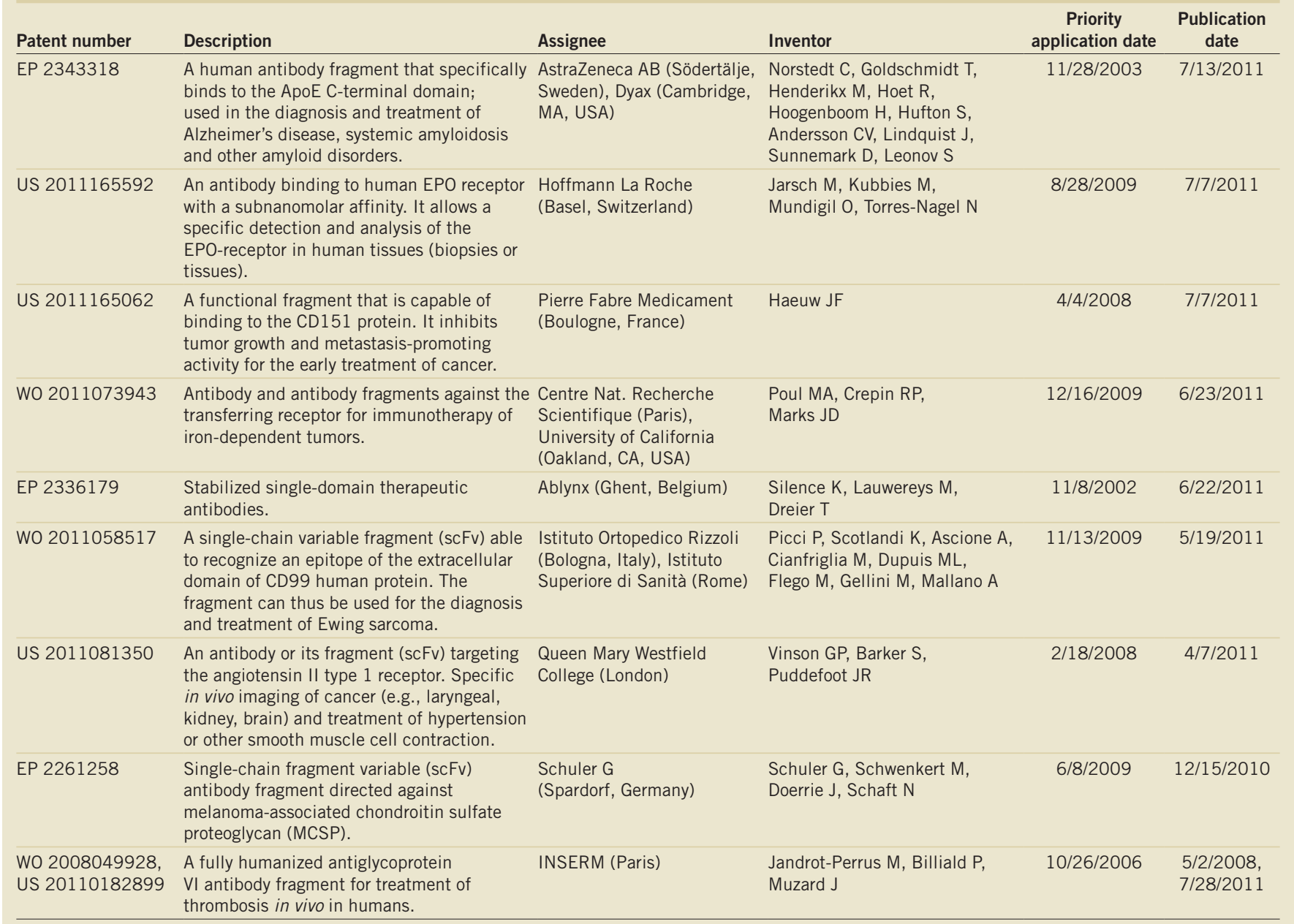

Source: US Patent and Trademark Office, Espacenet, JP and EP patent offices. The status of each application is slightly different from country to country. 